\title{
Uncoated Quartz Resonator as a Universal Biosensor
}

\author{
Tatiana Yakhno ${ }^{1}$, Anatoly Sanin ${ }^{1}$, Vyacheslav Kazakov' ${ }^{1}$, Olga Sanina ${ }^{1}$, \\ Christina Vacca ${ }^{2}$, Frank Falcione ${ }^{2}$, and Vladimir Yakhno ${ }^{1}$ \\ ${ }^{1}$ Institute of Applied Physics of Russian Academy of Sciences, \\ ${ }^{2}$ Aria Analytics, Inc., \\ ${ }^{1}$ Russia \\ ${ }^{2} U S A$
}

\section{Introduction}

Quartz Crystal Microbalance (QCM) sensors are widely used to perform medical diagnostic testing of biological liquids. These sensors have coatings that selectively bind specific chemicals or structures. This binding affects the acoustic properties of the liquid such as velocity, attenuation and frequency. Based on this approach, rapid detection of fibrinogen and fibrin degradation products was developed (Aizawa et al, 2004); bacteria, immunoglobulins, and C-reactive protein were detected (Muramatsu et al., 1989; Chue et al., 1996); different human blood cells can be detected (Konig, \& Gratzel, 1993a; 1993b). Also QCM sensors with special coatings can be used as gas-sensors (Zhou et al., 1994; Lazarova et al., 1996). Uncoated QCM sensors are commonly used for mass measuring in static and dynamic conditions (Gomes, 2001; Yamasaki et al., 2004). The measured frequency shift is proportional to the mass of the deposited film, so the sensor provides thickness data by measuring the film density and acoustic impedance. Another utilization of QCM sensors is measuring viscosity of liquids (Martin \& Ricco, 1987).

In the classical QCM sensor technique, the evaporation of solvent is viewed as a significant technical hurdle. We propose a modification of the QCM technique, which takes advantage of this previously undesirable process. The monitoring of a sample (a small $3 \mu \mathrm{l}$ or $5 \mu \mathrm{l}$ droplet) as solvent is evaporated provides unique insight into the transitions between physicochemical states of the tested liquid. Increasing the concentrations of solutes as solvent is removed allows probing of a series of states from dilute to concentrated, which may include aggregated, gel, and crystalline states. Using an uncoated quartz resonator as a sensor and measuring the changes of the Acoustic and Mechanical Impedance (AMI) over time, enables detailed monitoring of dynamics of molecular rearrangements in the drying sample droplet. In the proposed method, a single sensor demonstrates, over time, a change in its relative sensitivity to the contributions of different molecules to the measured signal, which is equivalent to using a large array with multiple sensors with unique sensitivity to various molecular components of the tested liquid.

A drop of liquid, drying on a solid substrate, is a natural model of a self-organizing system. There are many variants of the drying processes such as drop volume, environment,

Source: Intelligent and Biosensors, Book edited by: Vernon S. Somerset,

ISBN 978-953-7619-58-9, pp. 386, January 2010, INTECH, Croatia, downloaded from SCIYO.COM 
substrate properties, and liquid composition (Deegan, 2000; Deegan et al., 2000; Ragoonan \& Aksan, 2008; Yakhno, 2008, Yakhno \& Yakhno, 2009). Thus, if we control all outer parameters except liquid composition, only this parameter will be responsible for selforganizing processes in the drying drop. Self-organizing processes in drying protein solutions were first reported by E. Rapis (Rapis, 1988). L.V. Savina (Savina, 1999), V.N. Shabalin and S.N. Shatokhina (Shabalin \& Shatokhina, 2001) used this phenomenon in medical diagnostics. Morphology of human biological fluids is based on comparing the structure of dry drops of biological fluids of people in normal state to those of people with different diseases. However, such an approach has drawbacks, including the subjective estimate of structures, the difficult formalization of results, and the necessity of using expensive optical equipment and computer software for video-image processing. Moreover, the morphological analysis of dry drops is usually performed only after the complete drying (film water evaporation), which takes no less than two days.

a
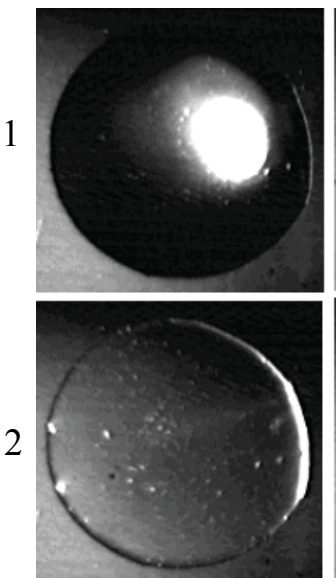

3

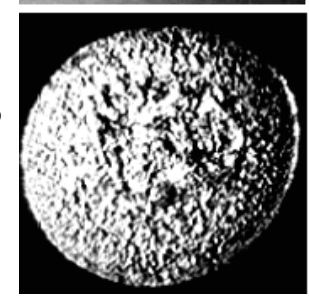

b
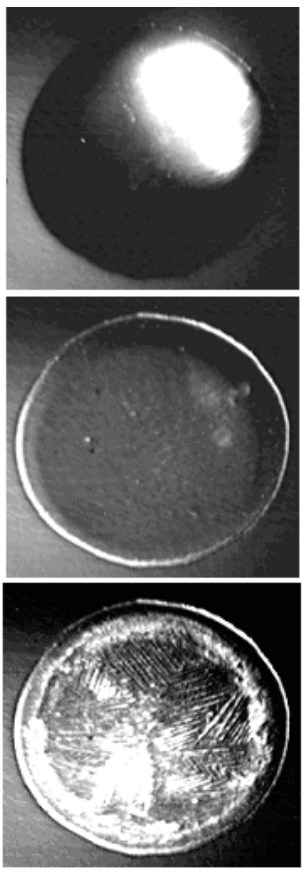

$\mathrm{c}$
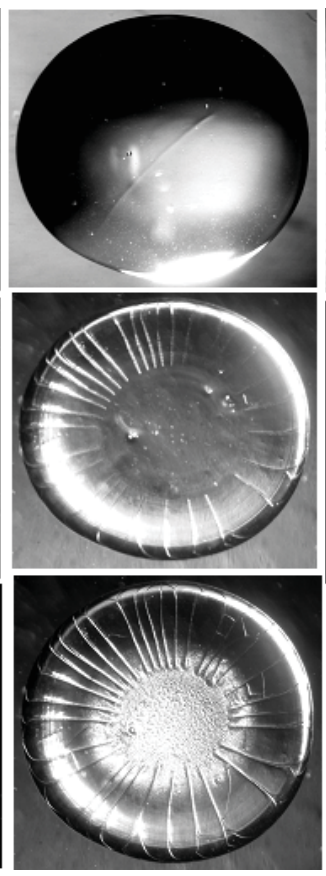

d
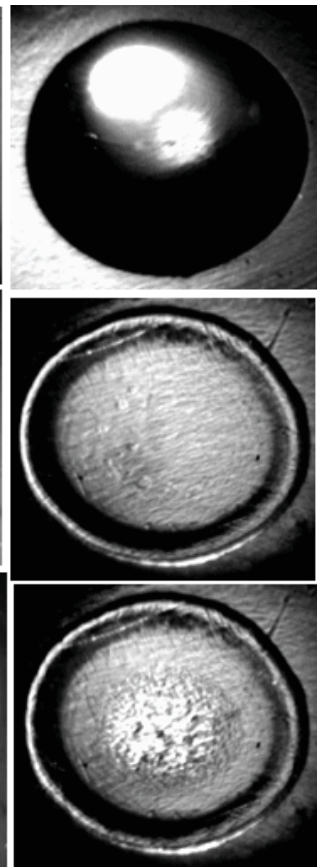

Fig. 1. Phase transitions in drying drops of (a-c) urine, saliva, and blood serum, respectively, of a healthy donor and (d) blood serum of a patient with hepatitis B: (1) beginning of drying; (2) gel matrix formation; (3) salt crystallization into gel (Yakhno et al., 2004).

We showed that, during free water evaporation, it is possible to get diagnostic information not only from morphological features of dried drops, but also from dynamic parameters (Yakhno et al., 2001). It allowed us to shorten the measurement time to 30-40 min, although subsequent treatment of the results was cumbersome. At that time we took photographs of drying drops every minute, made collages of pictures, and measured dynamics of structurization - average velocity, acceleration, and front propagation length from the edge 
to the center of the drop. In spite of the fact that we got significant difference between donors and patients with different diseases, it was clear, that more efficient way should be developed. Thus, quartz sensor setup was created for registering the dynamics of drop drying process (Yakhno et al., 2002). It is important to note, that the measuring procedure did not visibly disturb the self-organizing processes in drying drops, and they kept the same central symmetry zones as the drops, when dried on a glass substrate. In 2006 A. Killeen and coauthors (Killeen et al., 2006) confirmed the fact that the dynamics of pattern formation created by drying droplets of serum on cover slips differed when comparing normal samples to those containing monoclonal proteins. The authors came to this conclusion by registering the image dynamics in different parts of $1 \mu l$ serum droplets during drying. Subsequent treatment of these data by special software (Support Vector Machine classifier) also allowed quantitative separation of myeloma and normal serum samples.

a

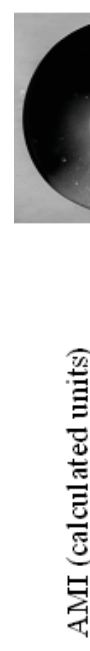

b

(1)
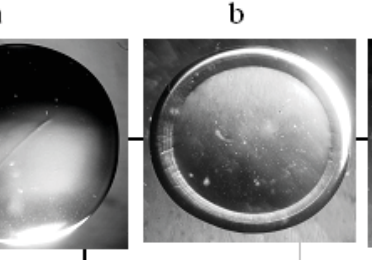

60

60

c
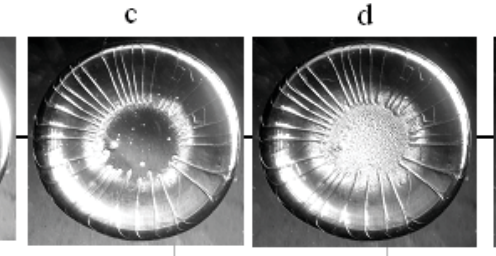

d

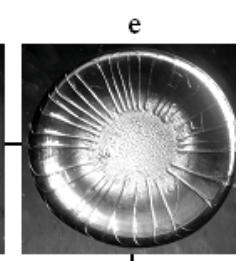

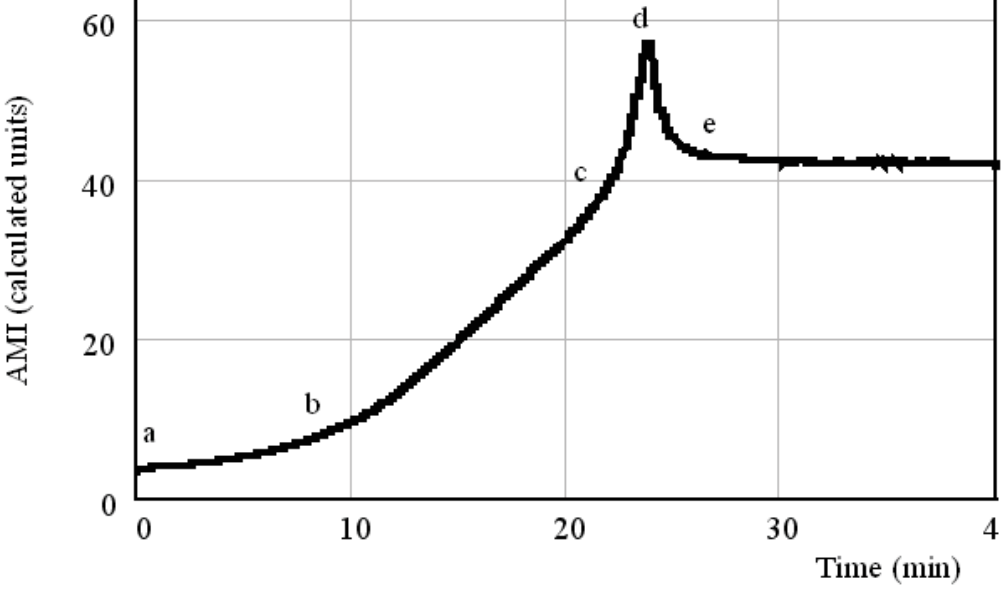

Fig. 2. Dynamics of phase transitions in drying drop of blood serum and its reflection in the different portions of the AMI curve: $(a-b)$ a drop's dome flattening and protein ring forming over the circle; (b-c) gel forming process into the drop; (c-d) salt crystallization process; (d-e) free water evaporation and achieving equilibrium. It expresses a final dried drop mass with film water.

A drop drying process of blood serum begins with phase transitions of proteins, and protein phase perturbations are finished by forming of a gel matrix (Yakhno et al., 2004). The final stage of drop drying involves salt crystallization in the residuals of liquid phase immobilized into gel (Fig. 1). If a drop dries on the surface of a quartz resonator, the drop self-organization is represented by the dynamics of phase transitions that are recorded using variation in the AMI. The kinetics of water evaporation during the phase transitions of salts 
is determined by physical properties of the gel, thus, it can charachterize liquid as a whole. Also it was established that the dynamics of AMI signal variation corresponds to the sequential stages of structure formation in a drying drop, and can be used for their description (Fig. 2). Thus, a shape of a curve "AMI vs. time" reflects features of drop drying dynamics. Different heuristic algorithms for parameterization the shape of AMI curves were developed. Comparing the dynamics of self-organization in drying drops of blood plasma with the help of these algorithms - Shape Indices (SI) - it was possible to distinguish different diseases on the plane of features (Yakhno et al., 2005).

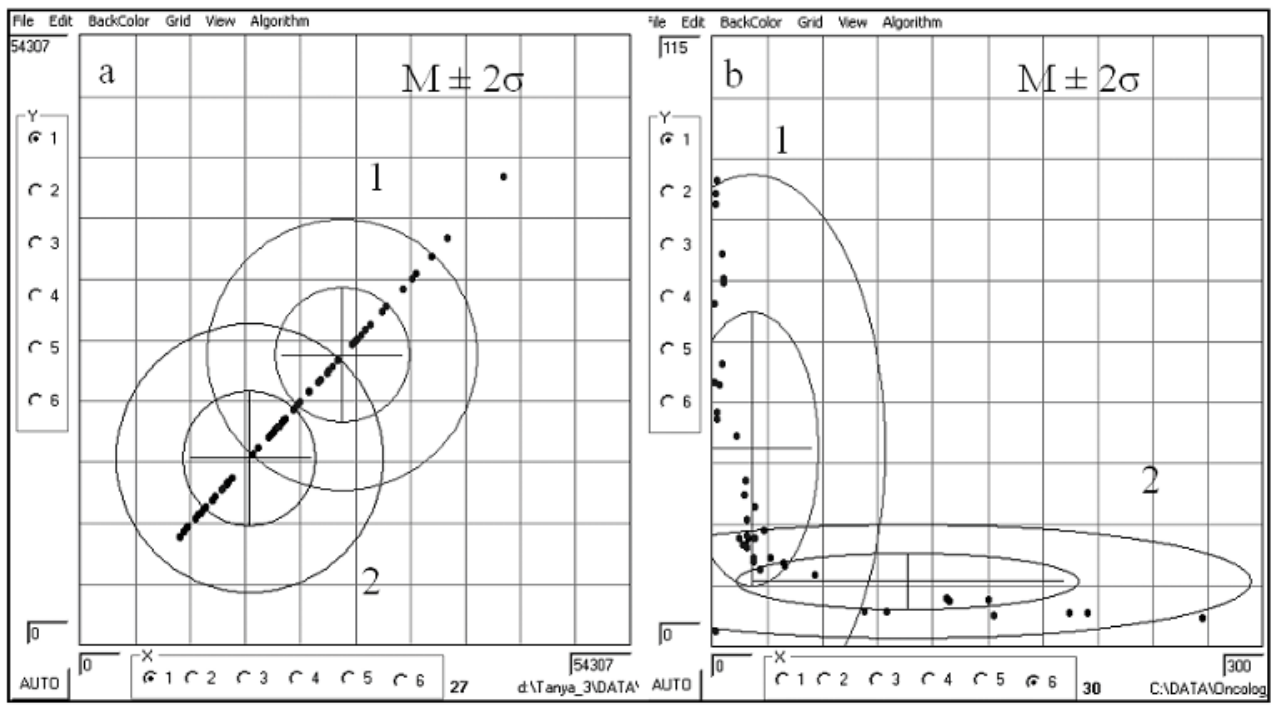

Fig. 3. Distribution of the data of breast cancer women (1) and donors - women of the same age (2) on the plane of features in coordinates of different SIs $(M \pm 2 \sigma)$. Blood serum (a) and urine (b) both contain diagnostic information.

The fact is diagnostic information can be extracted not only from serum, but also from urine (Fig. 3). There were shown that sensitivity and specificity for oncology case detection (total) was $76 \%$ and $100 \%$ respectively. These indices for breast cancer diagnostic were $92 \%$ and $86 \%$; for lung cancer diagnostics - $96 \%$ and $73 \%$; for paraproteinemia hemoblastosis - $100 \%$ and $100 \%$. Furthermore breast cancer and lung cancer could be separated from each other with sensitivity $93 \%$ and selectivity $73 \%$. There was also shown good prospects in gestation and threatened abortion diagnostics (Fig. 4). These aptitude tests used a drying drop as a "black box" with very complex processes into it during drying. We come to know the particulars of these processes using model protein and salt water solutions, which mimic human serum (Yakhno et al., 2007a; Yakhno et al., 2007b; Yakhno, 2008). As long as some deseases are accompanied by high level of immunoglobulines, and different levels of fibronectin (Fn) in blood serum (Heil, W. et al., 1999), we would like to see what changes in shape of the AMI curves take place when some of these serum components are added to the Human Serum Albumin (HSA) solution. The aim of this work was to trace some causal relationships, which were responsible for diagnostic data, using model protein-salt solutions of different content and structure. 


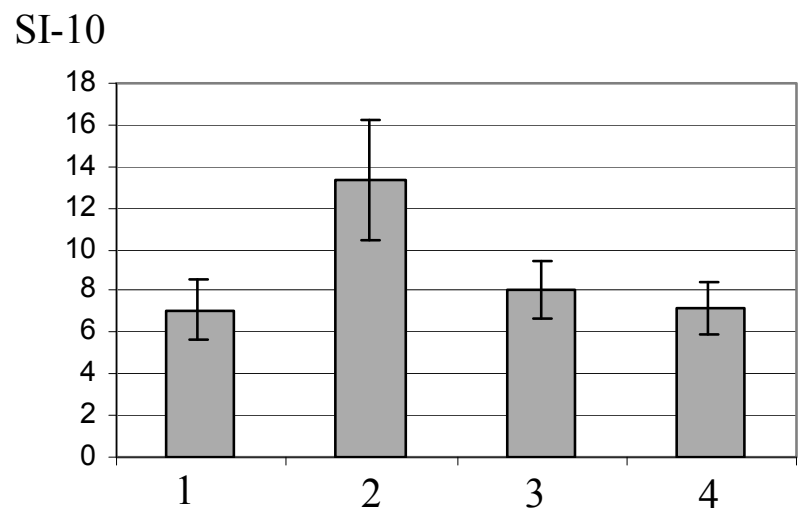

Fig. 4. SI-10 value in women - donors (1), normal pregnancy women (2), pregnancy women with threatened abortion (3), and women after premature birth (4).

\section{Methods and materials}

\subsection{Device description}

A drop is dried on the surface of a quartz sensor, while it oscillates in the shear mode. The quartz sensor is a resonator in the form of a rectangular bar of quartz XYS/ $1^{\circ} 30^{\prime}$ with section 48.0 by 4.8 by $1.0 \mathrm{~mm}$. (Fig. 5). Electrodes on which sinusoidal voltage is fed to excite mechanical oscillations are applied on the upper and bottom plane faces. The resonator is suspended by wire conductors soldered to the bar in the middle. The operating mode is the mode of longitudinal bulk oscillations of the bar, i.e., the mode of compressiondecompression oscillations in the direction of the length. The operating frequency of the excitation voltage corresponds to the frequency of the first longitudinal resonance of the bar, i.e., the bar length corresponds to one a half of the length of the longitudinal sound wave in the resonator $(60 \mathrm{kHz})$. In this case, the distribution of the oscillatory velocity amplitude over the plate length has a sinusoidal form with a zero value in the middle of the length. A drop of a liquid under study is placed at the surface on the operation end of the bar, where the oscillatory velocity amplitude of the surface is approximately constant. Part of the area of the electrodes on the operating end of the sensor is removed (Fig. 5) to place the drop directly on the polished surface of a quartz crystal. Shear displacements of all side faces of the bar occur under bulk oscillations in the direction of the length. Under such conditions, the drop is an acoustical (mechanical) load of the resonator for shear oscillations. The AMI is a value of this load. The amplitude of mechanical oscillation is chosen such that to make the minimum disturbance for self-organization processes.

The AMI of a drop is determined from the electric conductance of the resonator operated at a fixed frequency, which is equal to the resonance frequency of the unloaded resonator. For the AMI measurements, we used bridge circuit, which allows cancellation of the static resonator capacitance and provides for an imbalance voltage that is inversely proportional to the modulus of the AMI (Yakhno et al., 2003). 


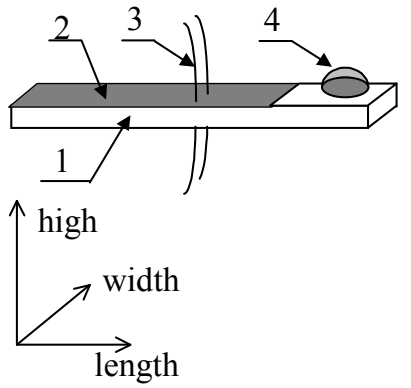

A

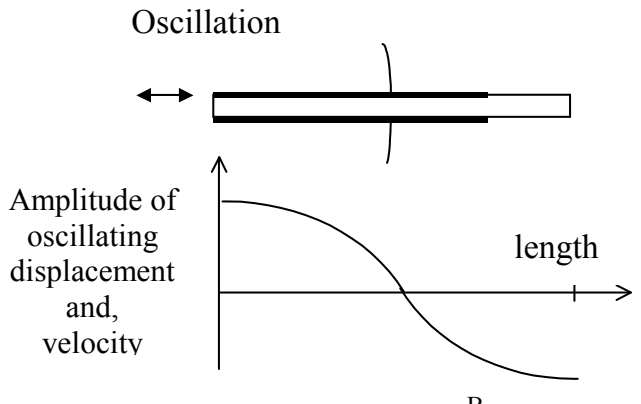

B

Fig. 5. Design and oscillation mode of a quartz resonator. A is a quartz resonator with a drop of studied liquid, 1 is a quartz plate, 2 is the metallization, 3 is the supporting conductors, and 4 is a drop of studied liquid. B is the distribution of the oscillatory velocity amplitude and longitudinal displacement.

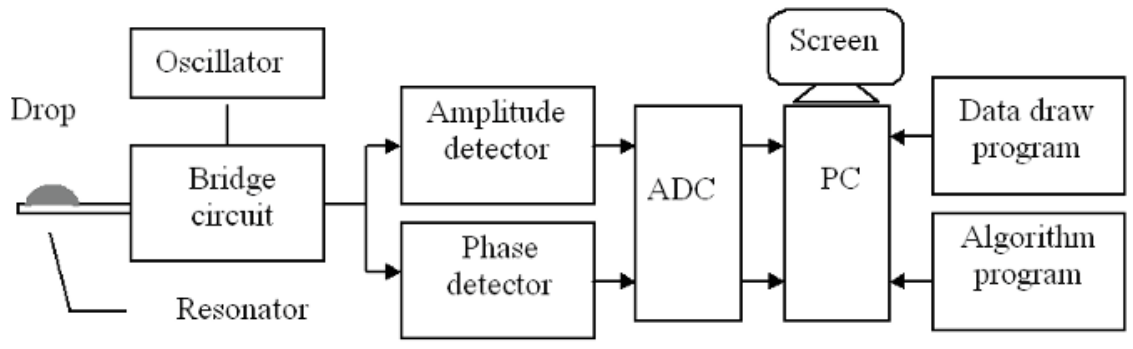

Fig. 6. Block diagram of the device for measuring the AMI dynamics.

A block diagram of the device is shown in Fig. 6. An amplitude detector detects the output voltage of the bridge circuit. Detected signal is fed through an analogue-to-digital converter $(\mathrm{ADC})$ to a personal computer (PC). The drop drying process is displayed on the screen in the form of an amplitude curve corresponding to the modulus of the AMI (Fig. 6). A more detailed description of the device construction and measurement procedure can be seen also in (Yakhno et al., 2003; Yakhno et al., 2005).

Actually, the AMI is a complex value, which is the sum of acoustical and mechanical impedances. Each of them has its own "weight coefficient": H1, H2, H3, and H4. These coefficients and their temporal changes during the drop drying depend on the liquid (its content, structure, etc).

$$
\mathrm{AMI}=\mathrm{H} 1(1+\mathrm{j}) \mathrm{S} \sqrt{\pi \mathrm{f} \rho \eta}+\mathrm{H} 2 \mathrm{j} 2 \pi \mathrm{fm}+\mathrm{H} 3 \frac{\mathrm{k}}{\mathrm{j} 2 \pi \mathrm{f}}+\mathrm{H} 4 \mathrm{kfric}
$$

where $\mathrm{j}$ is an imaginary unit, $\mathrm{S}$ is the square of liquid-solid interface, $\mathrm{f}$ is the frequency of resonator oscillation, $\dot{\eta}$ is the liquid viscosity, $\rho$ is the liquid density, $m$ is the loading mass; $k$ is the elasticity, and the kfric is the friction coefficient.

At the beginning of drying, when a drop is a liquid, its impedance is proportional to the specific resistance of a shear wave (Mason, 1964): 


$$
\mathrm{AMI}_{\text {beg }}=\mathrm{H} 1(1+\mathrm{j}) \mathrm{S} \sqrt{\pi \mathrm{f} \rho \eta}
$$

where $\mathrm{AMI}_{\text {beg }}$ is the AMI value at the beginning of drying. Usually $\eta \sim 10^{-2} \mathrm{~Pa} \cdot \mathrm{s}$, and $\rho \sim$ $10^{3} \mathrm{~kg} / \mathrm{m}^{3}$ for the liquids under study. Under these conditions the height of the drop does not influence the AMI value, because at the set frequency the shear wave penetration depth is approximatelly $10 \mu$ (Mason, 1964). Therefore the beginning of drying is represnted by equation (1) where coefficient $\mathrm{H} 1=1$, and $\mathrm{H} 2=\mathrm{H} 3=\mathrm{H} 4=0$. When drying is complete solid sediments usually adsorb to the quartz plate and the resonator is loaded with the impedance of co-oscillated mass $\mathrm{m}_{\mathrm{end}}$ of these residuals:

$$
\mathrm{AMI}_{\text {end }}=\mathrm{H} 2 \mathrm{j} 2 \pi \mathrm{fm}_{\text {end }}
$$

where $\mathrm{AMI}_{\text {end }}$ is the $\mathrm{AMI}$ value at the end of drying, $\mathrm{m}_{\mathrm{end}}$ is mass of dried residuals. Therefore at the end of drying process weight coefficient $\mathrm{H} 2=1$, and other ones $\mathrm{H} 1=\mathrm{H} 3=$ $\mathrm{H} 4=0$. Correspondence of AMI level to the equations (2) and (3) at the beginning and the end of drop desiccation was examined experimentally by measuring the real and imaginary parts of electrical conduction of the resonator (or by measuring the real and imaginary parts of AMI). It was shown that the very initial and the final stages of drying can be described by the equations (2) and (3). However such simple situations as "a liquid drop at the beginning" and "a solid mass at the end" are not usual. For example, some liquids have unequal real and imaginary parts of AMI, in contrast with (2), or liquids can have non-zero real parts at the end of drying, in contrast with (3). Registering AMI using share wave mode is a crucial factor for this technology, because it provides a high sensitivity of the AMI level for genesis and growth of new phase structures on the liquid-quartz border, as well as the acoustical and mechanical properties of resultant sediments.

\subsection{Liquids under study}

Protein-salt solutions were prepared using either lyophilized bovine serum albumin (BSA, $68 \mathrm{kDa}$ ) or human serum albumin (HSA, $67 \mathrm{kDa}$ ) in distilled water or salt-in-water solutions. Albumins were purchased from Sigma (USA). Salts $(\mathrm{NaCl}, \mathrm{KCl})$ were labeled "chemically pure" ("Reaktiv, Inc.", Russia). Other human blood serum proteins were obtained from "IMTEK, Ltd." (Russia): immunoglobulin G (IgG, 150 kDa), immunoglobulin $\mathrm{M}(\mathrm{IgM}, 900 \mathrm{kDa})$, and Fibronectin (Fn, $420 \mathrm{kDa})$. All solutions were prepared a day prior to experimentation, refrigerated overnight and allowed to come to room temperature before testing. For morphological analysis, $5 \mu \mathrm{l}$ drops of test solutions were placed on clean glass slides and air-dried at room conditions for two days. The preparations were examined and photographed using an MBI-3 microscope fitted with a Canon digital camera.

Protein content in human blood serum model solutions varied from $70 \mathrm{~g} \mathrm{l}^{-1}$ to $86.4 \mathrm{~g} \mathrm{l}^{-1}$. This coincides with the normal total protein concentration in human serum (Heil, W., et al., 1999). Every protein mix had a corresponding HSA control solution of the same protein mass (Tab. 1) and was dissolved in physiological $\mathrm{NaCl}$ solution $\left(9.0 \mathrm{~g} \mathrm{l}^{-1}\right)$. As a nonionic surfactant, we used OP-7 $\left(\mathrm{O}\left(\mathrm{CH}_{2} \mathrm{CH}_{2}\right) \mathrm{nCH}_{2} \mathrm{CH}_{2} \mathrm{OH}\right)$ (GOST 8433-81, Russia). Every protein variation was tested at least 10 times. All samples under comparison were tested under the same laboratory conditions $\left(\mathrm{T}=18-22^{\circ} \mathrm{C}, \mathrm{P}=740-760 \mathrm{~mm} \mathrm{Hg}\right.$, and $\left.\mathrm{H}=60-70 \%\right)$. Table 1 below summarizes the protein content of the protein-salt samples. 


\section{Results and discussion}

Typical shapes of the AMI curves of protein-salt solutions and distribution of the data on a plane of features (SI-1 vs. SI-3) are represented at Figure 7. Adding the micro quantity of fibronectin to the HSA salt solution (Tabl. 1) results in left shift of the AMI curve, and changes the geometry of saline peak. As an example of formalization the changes in the shape of the AMI curves we used Shape Index 1 (in calculated units), which is based on the value of averaged derivative of the ascending part of the AMI curve. For every the AMI curve this segment is determined as a time of salt crystallization (Fig. 8, internal brace), which was placed to left (Fig. 8, external brace), so, measuring part of the curve was limited by the angle $\mathrm{A}$, as it is shown at the picture.

\begin{tabular}{|c|l|c|c|c|c|c|}
\hline № & Protein composition & $\begin{array}{c}\text { [Total protein] } \\
\mathrm{g} \mathrm{l}^{-1}\end{array}$ & $\begin{array}{c}{[\mathrm{HSA}]} \\
\mathrm{g} \mathrm{l}^{-1}\end{array}$ & $\begin{array}{c}\text { [Fn] } \\
\mathrm{g} \mathrm{l}^{-1}\end{array}$ & $\begin{array}{c}{[\mathrm{IgG}]} \\
\mathrm{g} \mathrm{l}^{-1}\end{array}$ & $\begin{array}{c}\text { [IgM] } \\
\mathrm{g} \mathrm{l}^{-1}\end{array}$ \\
\hline 1 & HSA & 70 & 70 & - & - & - \\
\hline 2 & HSA+Fn & 70.4 & 70 & 0.4 & - & - \\
\hline 3 & HSA+Fn+IgG & 86.4 & 70 & 0.4 & 16 & - \\
\hline 4 & HSA (control 1) & 86.4 & 86.4 & - & - & - \\
\hline 5 & HSA+Fn+IgG+IgM & 84.5 & 70 & 0.3 & 12 & 2.2 \\
\hline 6 & HSA (control 2) & 84.5 & 84.5 & - & - & - \\
\hline
\end{tabular}

Table 1. Protein Content in Protein-Salt Solutions

Looking at the picture (Fig 1, b,c), we can see that HSA solutions contaning IgG, and IgG+IgM, differ in the shape of the AMI curves from corresponding control solutions that contane only HAS of the same concentrations (Table. 1). It is interesting that adding Fn to HSA leads to decrease in Shape Index 1, whereas replacement of a part of HSA to the same mass of immunoglobulines in solutions leads to increasing in it (Table 2). Fn is the most investigated glycoprotein of intercellular martix (Nikolaev, 1998). It participates in reparation processes in the tissues, forming a net, which works as a skeleton for the cells occupying a wound area. Fibronectin also plays an important role in opsonization of bacteria (Gilot et al., 1999). The decreasing in Shape index 1 after Fn adding in our experiments means that salt crystallization processes in drying drops carryed out more slowly than in drying drops of HSA solution. We believe that this is a result of protein consolidation at the drop-air border due to Fn net formation. Thus, Fn in drying drop can manifest its native function.

\begin{tabular}{|l|c|}
\hline Protein solution & Shape index 1 $(\mathrm{M} \pm \sigma)$ \\
\hline HSA & $12.0 \pm 0.1$ \\
\hline HSA+Fn & $10.9 \pm 0.4$ \\
\hline HSA+Fn+IgG & $16.6 \pm 0.8$ \\
\hline HSA (control 1) & $13.3 \pm 0.3$ \\
\hline HSA+Fn+IgG+IgM & $23.7 \pm 1.2$ \\
\hline HSA (control 2) & $13.4 \pm 0.5$ \\
\hline
\end{tabular}

Table 2. Shape index value for the AMI curves of protein-salt solutions. 


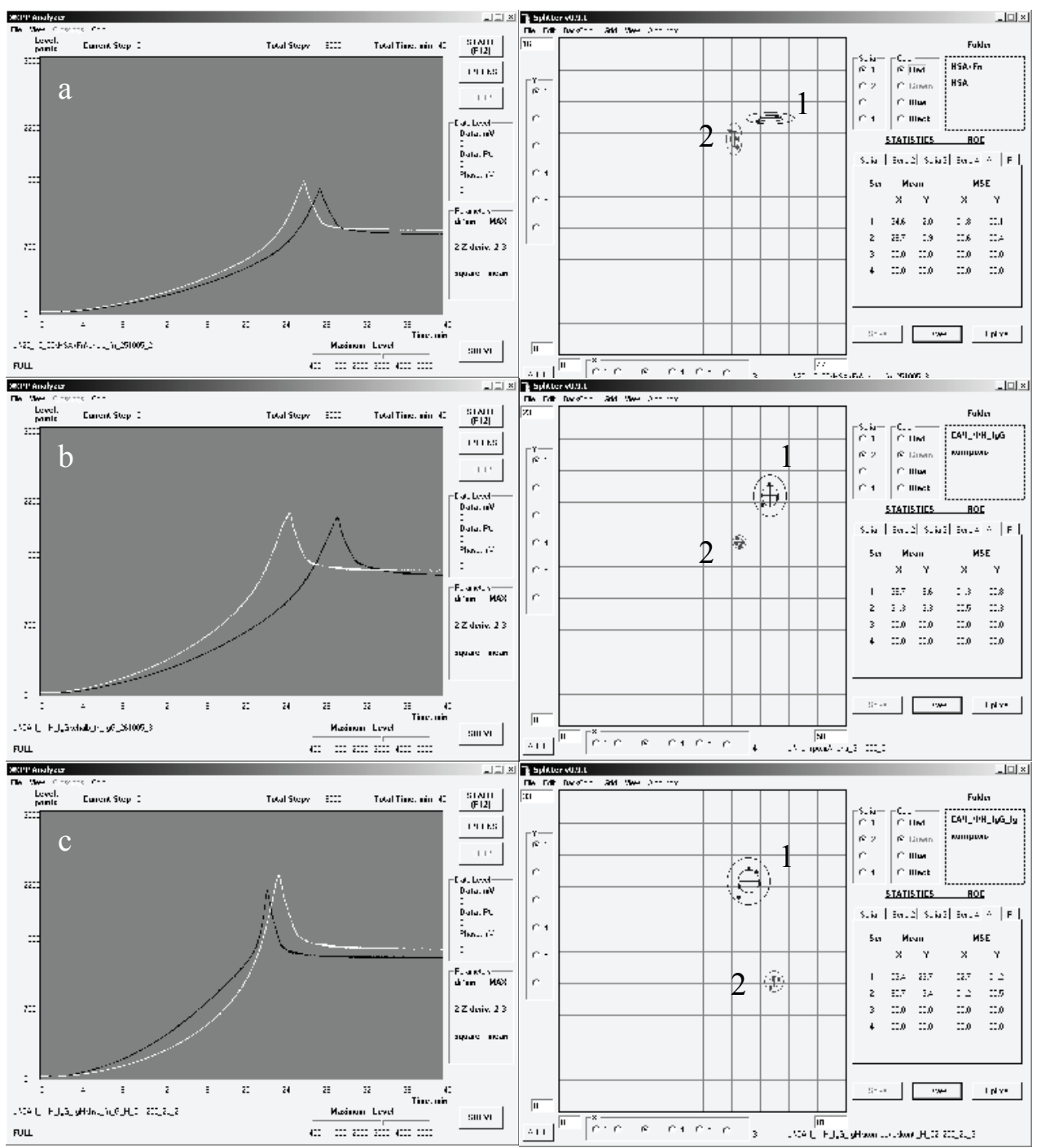

Fig. 7. Comparison of HSA solutions containing various human proteins in each case described in Table 1. Left, for every picture: X-axis is time (min), and Y-axis is AMI (calculated units); (a) HSA+Fn (white) and HSA (black); (b) HSA+Fn+IgG (white) and control 1 (black); (c) HSA+Fn+IgG+IgM (white) and control 2 (black). Right: corresponding data $(\mathrm{M} \pm 2 \sigma)$ on the plane of features (SI-1/SI-3), $\mathrm{M} \pm 2 \sigma$. For every picture 1 is protein mix under study, 2 is its control.

It is known that extension in size of surfactant molecule by one $\mathrm{CH}_{2}$ - unit, increases its surface energy in $3-3.5$ times, simultaneously its solubility in water decreases in the same range (Tchukin et al., 2004). Thus, we can dispose serum proteins an accordance with growth their surface activity the following way: HSA - IgG - Fn - IgM. It signifies that 


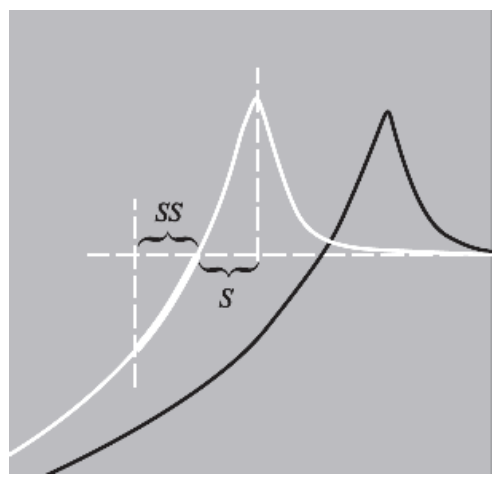

Fig. 8. Calculation of SI-1. The portion " $\mathrm{S}^{\prime \prime}$ is equal with the time of salt crystallization. The portion "SS" is the mirror image of portion "S". SI- 1 is calculated using these areas averaged derivative of the highlifhted segment of the curve.

immunoglobulines and Fn in drying drops must occupy the upper position, and act on water evaporation during drying. Because immunoglobulins have no mechanical functions in blood, in drying drop they conduct themselves as proteins with a high surface energy, and settle themselves on the drop-air border, resulting in a lowering of suface tension. This fact leads to increase in the area of the drop on the quartz sensor, and water evaporation becomes more intensive. So, salt crystallization becomes more rapid (SI-1 decreases). The lowring in surface tension of HSA solutions after adding immunoglobulines, as well as rise in surface tension after adding Fn, were shown by direct measurements (Yakhno et al., 2007a).

In addition, we tested BSA solutions $\left(70 \mathrm{~g} \mathrm{l}^{-1}\right)$ in either $\mathrm{NaCl}$ or $\mathrm{KCl}$ water solutions $\left(9 \mathrm{~g} \mathrm{l}^{-1}\right)$. The replacement of $\mathrm{NaCl}$ by $\mathrm{KCl}$ in the BSA solution led to manifest changes in the AMI dynamics as the drop dried (Fig. 9a). These differences are due to $\mathrm{Na}^{+}$and $\mathrm{K}^{+}$ion features, and their positions in the Hofmeister line, in accordance with their ability to salting-out proteins from solutions and to rise surface tension on the phase boders (Muschol \& Rosenberger, 1997; Curtis et al, 1998; Boström et al., 2004). Despite the fact that both solutions had the same protein/salt mass ratio, their initial ionic strength (I) was differerent: $\mathrm{I}(\mathrm{NaCl})=0.08$, and $\mathrm{I}(\mathrm{KCl})=0.06$. Thus, the ion charge and size play a significant role in the initialization and developing protein phase transitions in drying drops of protein solutions. Parametrization of the AMI curves by means of SI- 6 allows to represent these differences in a digital form. The Shape Index 6 is based on the maximum of the salt peak (Fig 9a, 1), the level of the right part of the curves (Fig. 9a, 2), and geometry of saline peak. For BSA+NaCl SI-6 was equal $514.7 \pm 40.4$, and for $\mathrm{BSA} \pm \mathrm{KCl}$ it was $324.5 \pm 19.0$.

We extended these experiments, and added to this line 7\% BSA water solutions in $0.9 \% \mathrm{wt}$ divalent clorides: $\mathrm{MgCl}_{2} \times 6 \mathrm{H}_{2} \mathrm{O}$ or $\mathrm{CaCl}_{2} \times 6 \mathrm{H}_{2} \mathrm{O}$. The results of parametrization is shown on Fig. 10 in coordinates of SI-1. The data were placed in accordance with the Hofmeister series, and were proportional to the surface charge density of the cations (Table 3). Keeping in mind that $\mathrm{K}+$ is a weak chaotrop $(\mathrm{K}+$ binds water more weakly than water binds itself), and the other cations are kosmotrops of different rates (they bind water stronger, than water binds itself), these properties are definded by value of Jones-Dole viscosity B coefficient. It is clear, that in the line from $\mathrm{K}^{+}$to $\mathrm{Mg}^{2+}$ cation hydrated radius increases due to bound water, it influence viscosity of the solutions (4), and reverberate in dynamical processes during drop drying. 


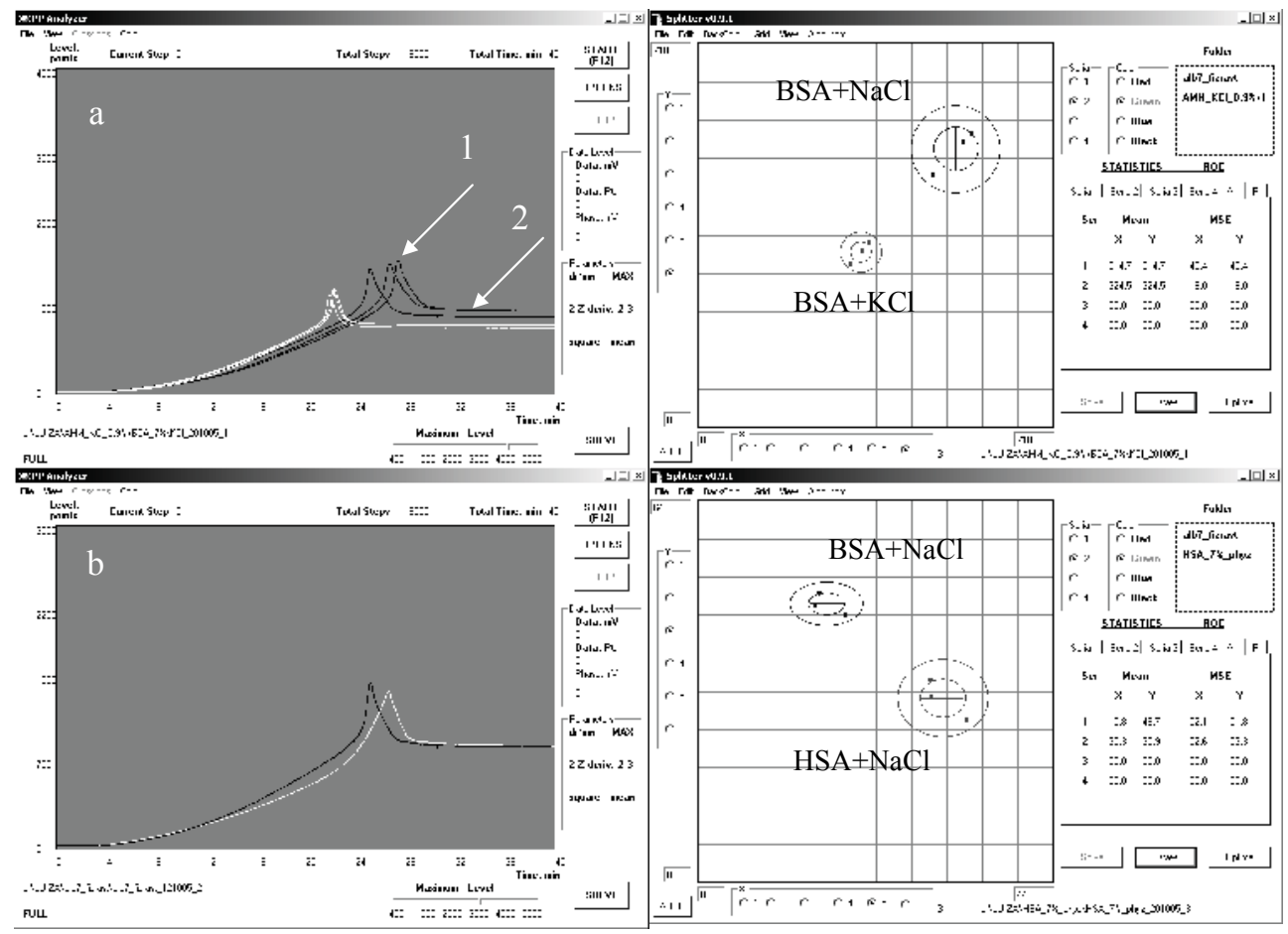

Fig. 9. Comparison of the solutions under study. Left, for both pictures: $X$-axis is time (min), and Y-axis is AMI (calculated units); (a) $\mathrm{NaCl}$ (black) vs. $\mathrm{KCl}$ (white) in BSA solution. 1 is maximum height of the salt peak; 2 is the level at which equilibrium is reached. (b) BSA (black) vs. HSA (white) in $\mathrm{NaCl}$ solution. Right - distribution of the data on plane of features $(\mathrm{M} \pm 2 \sigma)$. Above shows SI-6 vs. SI-6; bottom shows SI-3 vs. SI-5.

$$
\eta / \eta_{0}=1+A c^{1 / 2}+B
$$

$\eta$ - viscosity of an aqueous salt solution;

$\eta_{0}$ - viscosity of water at the same temperature;

C - concentration;

A - electrostatic term, and

B - a measure of ion-water interactions (Jones-Dole viscosity B coefficient)

The next series of experiments was aimed at tracing differences in drop drying processes when BSA and HSA at one and the same weight concentrations $\left(70 \mathrm{~g} \mathrm{l}^{-1}\right)$ were dissolved in $\mathrm{NaCl}$ physiological solution (Fig. 9b). We calculated Shape index 1, which was equal 8.7 \pm 0.5 , and $12.0 \pm 0.1$ for BSA and HSA solutions, consequently. Also we applied Shape Index 3, which is based on the value of averaged derivative of the descending part of saline peak of the AMI curve from its maximum to the constant the AMI value level. The Shape Index 3 was $46.7 \pm 1.8$ for BSA, and $11.1 \pm 0.6$ for HSA solutions. Thus, we can see that in drying drops of HSA salt solution, salt crystalization is a slower process than in BSA salt solution. We suggest that these distinctions are governed by the differences in molecular shape, as well as discharge value and distribution around them (Chang \& Bae, 2003). These initial protein 
features influence the properties of the protein gel and water diffusion throughout the entire drying process.

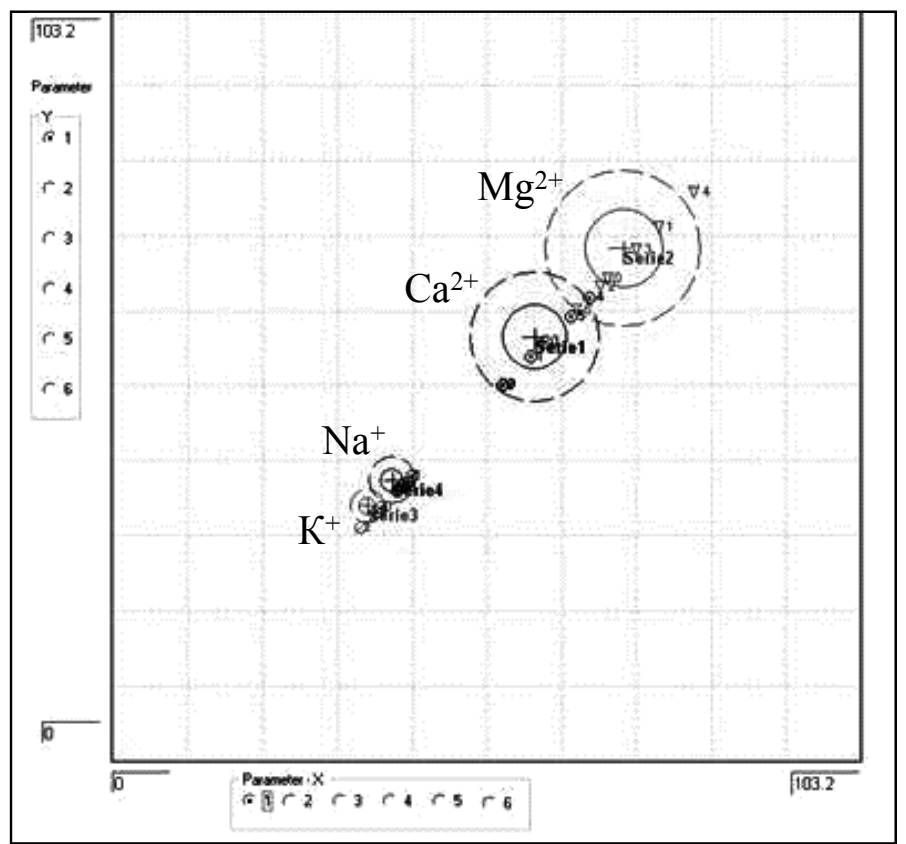

Fig. 10. Distribution on the plane of features 7\% BSA solutions in $0.9 \%$ different salt-in water solutions in accordance with Hofmeister Series $(\mathrm{M} \pm 2 \sigma)$ in coordinates SI-1 vs. SI-1.

\begin{tabular}{|c|c|c|c|c|}
\hline Cation & $\begin{array}{c}\text { Ion Radius } \\
(\mathrm{pm})\end{array}$ & $\begin{array}{c}\text { Surface area of } \\
\text { spherical ion (in } \\
\left.\mathrm{pm}^{2}\right)\end{array}$ & $\begin{array}{c}\text { Surface charge density } \\
\text { (Relative value) }\end{array}$ & $\mathrm{B}$ \\
\hline $\mathrm{K}^{+}$ & 138 & 239.3 & 0.59 & -0.007 \\
\hline $\mathrm{Na}^{+}$ & 102 & 130.7 & 1.06 & 0.086 \\
\hline $\mathrm{Ca}^{2+}$ & 100 & 125.7 & 2.24 & 0.285 \\
\hline $\mathrm{Mg}^{2+}$ & 72 & 65.1 & 4.3 & 0.385 \\
\hline
\end{tabular}

Table 3. Some physical-chemical parameters of the cations under study (Collins, 1997).

When a surfactant is added to protein solution, it begins to replace protein from the adsorptive layers, lowering the surface tension of the system (Joos \& Serrien, 1999). Ionic and nonionic surfactants have some differences in their action, but their main influence on the solutions is the same (Mackie et al., 2000; Gunninh et al., 2004). The adding nonionic surfactant to BSA salt solution stimulates the dose-dependent left shift of the AMI curves of drying drops (Fig. 11). Our microscopic investigations show that addition of surfactant reduces clustering of colloidal particles and gelation. Most strikingly, the addition of this surfactant systematically reduced the time required for the beginning of $\mathrm{NaCl}$ crystallization. The degree of drop cracking intensifies with increase in surfactant concentration. Furthermore, cracks show up earlier in the drop drying process. Gradual 
decrease of surface energy on the drop-air border eases water diffusion through the adsorbtive layer, and evaporation becomes more intensive. Because water is a plasticizer, its evaporation increases the fragility of the system, and leads the earlier and more intensive cracking of drying drops as the surfactant concentration increases. This dependence becomes apparent when we are looking at the AMI curves.

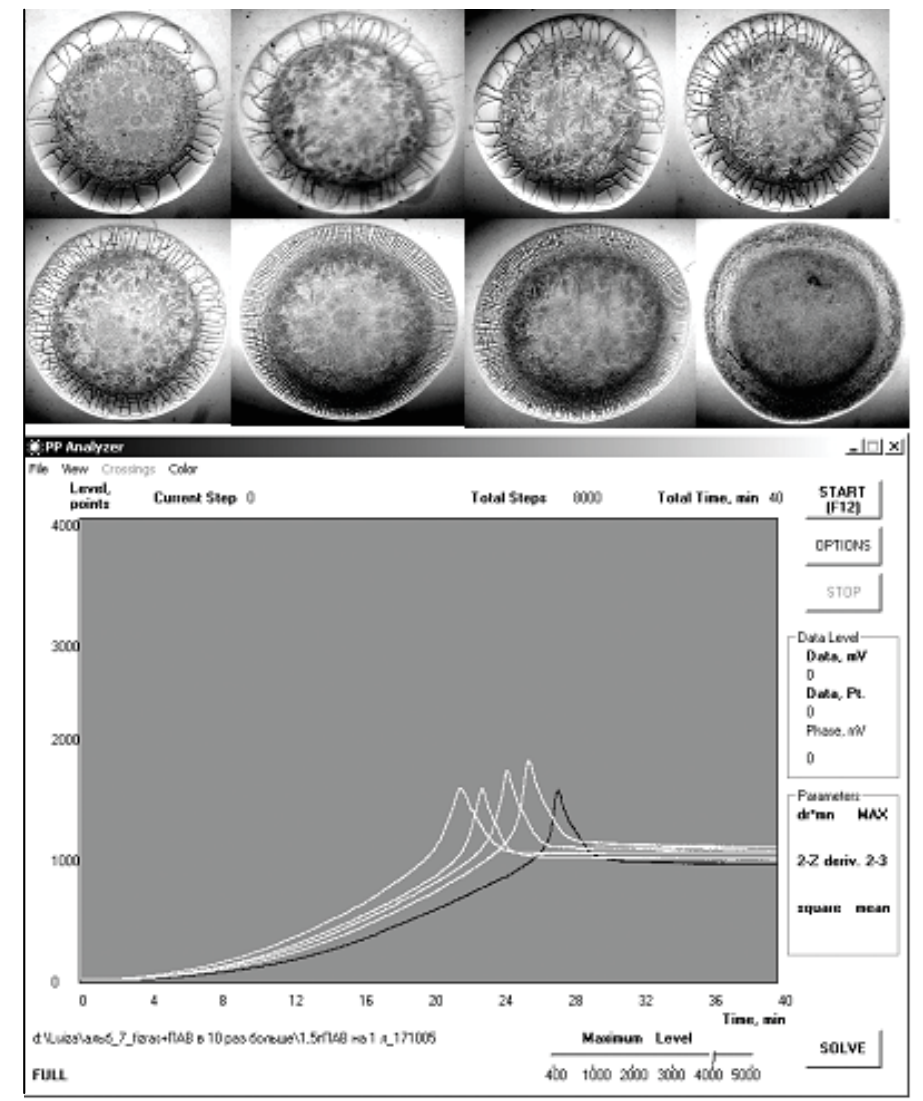

Fig. 11. Microimages (upper line) of dried drops of [BSA] $70 \mathrm{~g} \mathrm{l}^{-1}$ in $[\mathrm{NaCl}] 9 \mathrm{~g} \mathrm{l}^{-1}$ water solution, with adding nonionic surfactant in different concentrations (above), and dynamics of the AMI of the same solutions during drying (below). Surfactant concentration (drops, from left to right): $0,00 \mathrm{~g} \mathrm{l}^{-1} ; 0,05 \mathrm{~g} \mathrm{l}^{-1} ; 0,10 \mathrm{~g} \mathrm{l}^{-1} ; 0,15 \mathrm{~g} \mathrm{l}^{-1} ; 0,20 \mathrm{~g} \mathrm{l}^{-1} ; 0,50 \mathrm{~g} \mathrm{l}^{-1} ; 1,00 \mathrm{~g} \mathrm{l}^{-1}$; $2,00 \mathrm{~g} \mathrm{l}^{-1}$. Magnification is $\times 10$.

AMI curves (bottom line) of drying drops of the same solutions without surfactant (black), and after surfactant adding (white, from right to left): $0,20 \mathrm{~g} \mathrm{l}^{-1} ; 0,50 \mathrm{~g} \mathrm{l}^{-1} ; 1,00 \mathrm{~g} \mathrm{l}^{-1} ; 1,50 \mathrm{~g} \mathrm{l}^{-1}$. $\mathrm{X}$-axes is time (min), and Y-axes is the AMI (calculated units).

We also evaluated the effect of a magnetic field on the dynamic processes in drying drops of protein solutions (Fig. 12). The solutions under study were placed in a static magnetic field $(400 \mathrm{H})$, and were mixed with a plastic spoon for $10 \mathrm{~min}$. The solutions were then removed from the magnetic field, and underwent a measuring procedure. 


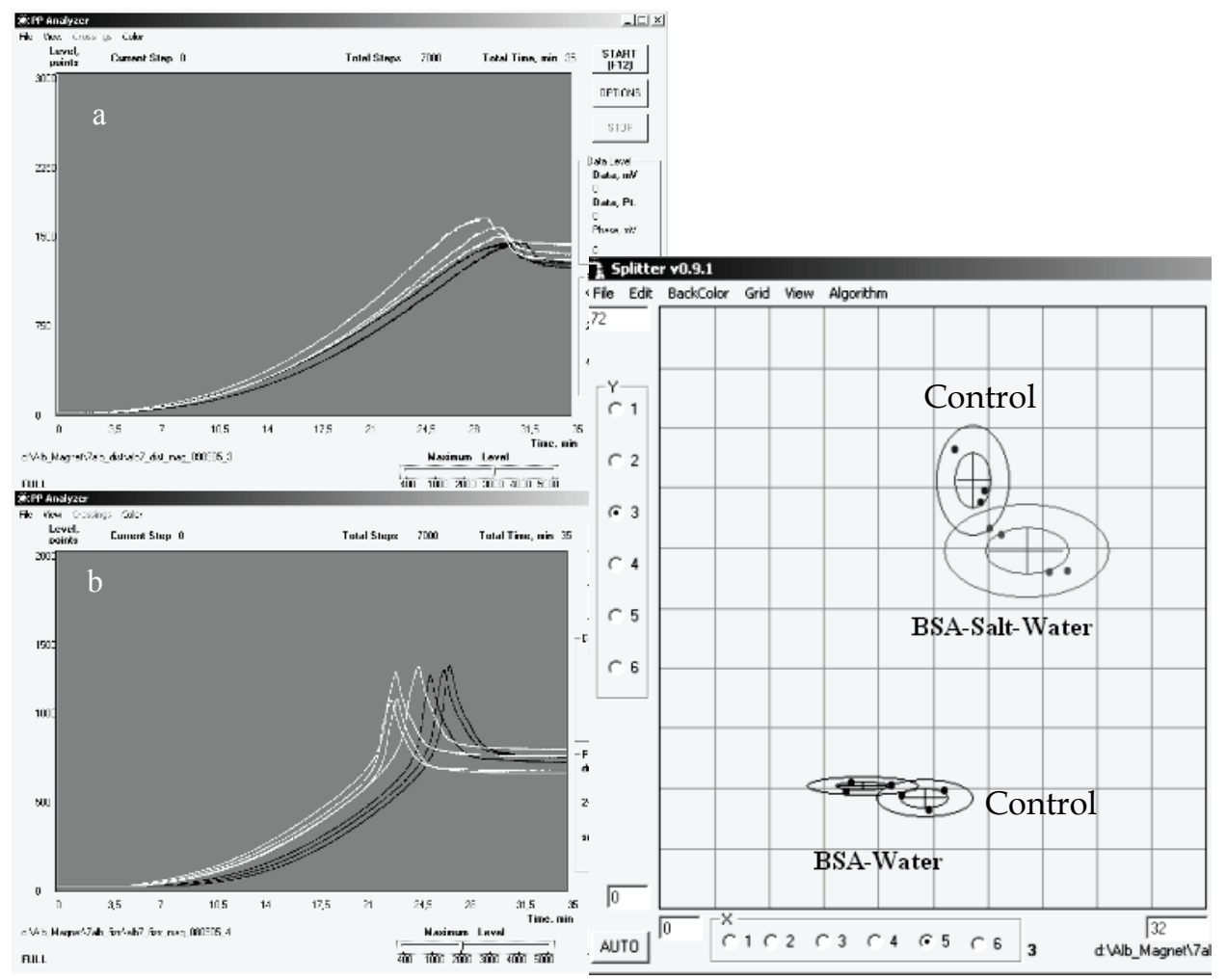

Fig. 12. Influence of magnetic field $(400 \mathrm{H})$ on the dynamic processes in drying drops of protein water solutions: Left (a) 7\% BSA in distilled water; (b) 7\% BSA in $0.9 \% \mathrm{NaCl}$ water solution. Black curves - control, white curves - after irradiation. X-axes is time (min), and Yaxes is the AMI (calculated units). Right - data distribution on a plane of features SI-3 vs. SI$5(\mathrm{M} \pm 2 \sigma)$.

Control samples also were mixed 10 min without contact with magnetic field and underwent the same measurement procedure. These results were also compared to our earlier studies (Yakhno et al., 2004) of the effect of UV-irradiation on the $0.5 \mathrm{mg} / \mathrm{ml}$ carboanhydraze solution in $0.9 \% \mathrm{NaCl}$ water solution by $\mathrm{XeCl}$ excimer laser exposure $(\lambda=$ $308 \mathrm{~nm}$ ) (Fig. 13). The extent of the UV-irradiation-induced protein damage was evaluated by fast protein liquid chromatography (FPLC system, Pharmacia Biotech). Before irradiation the protein solution was present in the form of monomers (Fig. 13, a1). Exposure to XeCl excimer laser radiation in a doze of $20 \mathrm{~J} / \mathrm{m}^{2}$ led to the appearance of dimers and molecular fragments (Fig. 13, a2). Upon a tenfold increase in the radiation dose, protein mostly occurred in the form of dimer, trimer, and polymer fractions with a considerable amount of molecular fragmentation (Fig. 13, a3). A change in the state of protein in solution was also indicated by the light-scattering ability of drops within the very first minutes of drying (Fig. $13, \mathrm{~b})$. The drops of solution that were not subjected to irradiation retained a homogenous structure up to the moment of salt crystallization. Irradiation of the protein solution in a dose of $20 \mathrm{~J} / \mathrm{m}^{2}$ led to a significant increase in the light scattering of drying drops as a result 


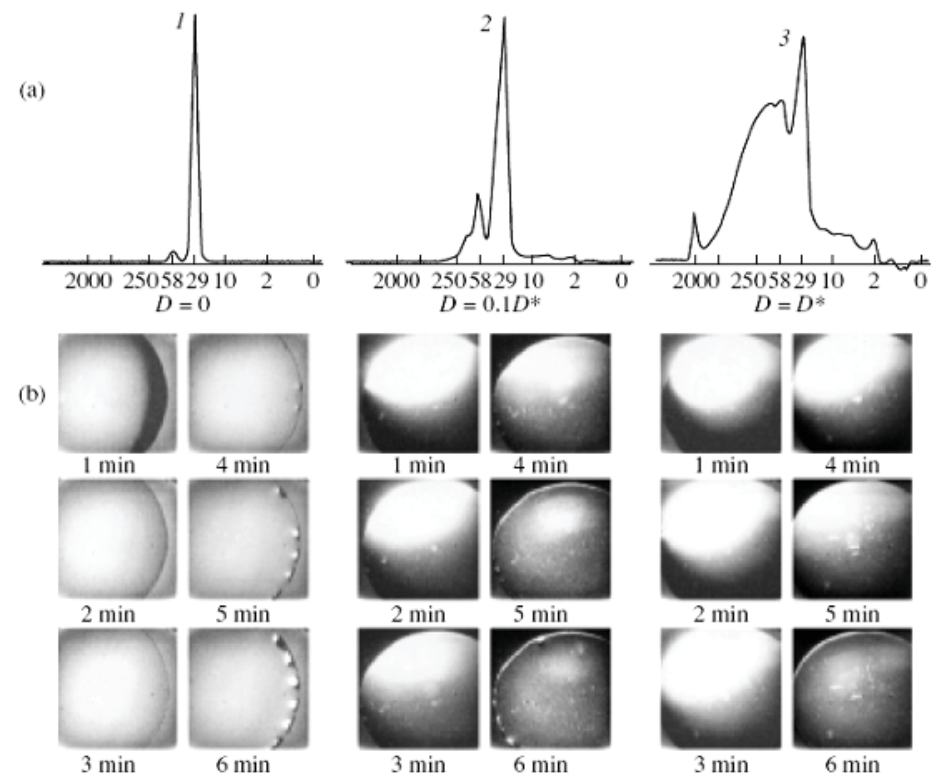

(c)

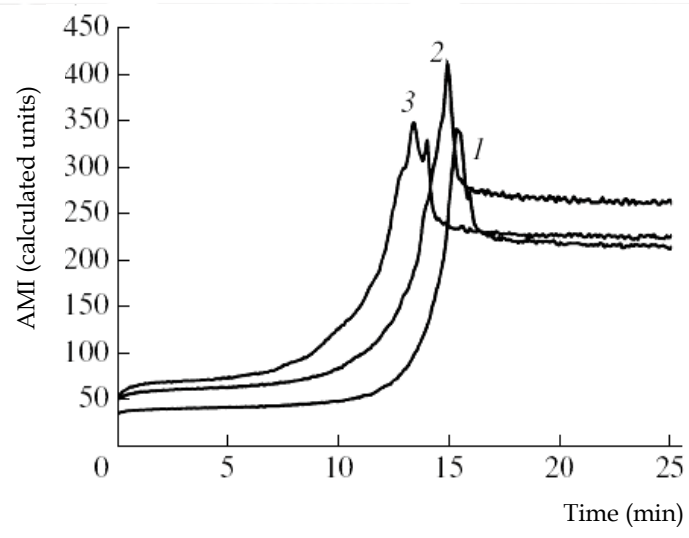

Fig. 13. The action of UV-irradiation on the $0.5 \mathrm{mg} / \mathrm{ml}$ carboanhydraze solution in $0.9 \%$ $\mathrm{NaCl}$ water solution (1) before and (2,3) after irradiation with a dose of 20 and $200 \mathrm{~J} / \mathrm{m}^{2}$, respectively: (a) molecular mass distribution; (b) pattern formation of light scattering during the first six minutes of drops drying. (c) AMI dynamics of the solutions (1) before and $(2,3)$ after UV irradiation in a doze of 20 and $200 \mathrm{~J} / \mathrm{m}^{2}$, respectively.

of protein aggregation, and was accompanied by the formation of a coarse protein matrix with an admixture of protein aggregates (Fig. 13, b2). An increase in the radiation dose to $200 \mathrm{~J} / \mathrm{m}^{2}$ led to very rapid aggregation of the damaged protein: massive aggregates precipitated on the substrate within one minute and did not take part in subsequent events (Fig. 13, b3). Acceleration of the protein aggregation and its precipitation on the quartz crystal surface upon irradiation are manifested by the radiation-dose-dependent leftward shift of the ascending part of the AMI curves (Fig. 13, c). 


\section{Conclusion}

Studies presented here demonstrate the unique use of an uncoated quartz resonator in the diagnostics of multicomponent liquids without detection of their content. This is a new type of analytical instrument, based on nonlinear nonequilibrium processes in drying drops, socalled self-organization. The main feature of this approach is that phase transitions in drying drops were registered and used as the informative parameter. Here every component displayed its physical-chemical properties in the solution, and also their influence the total drying process. Addition of Immunoglobulins and Fn to the solutions demonstared opposite effects on the drying process. These effects can be related to their different native functions in blood. Our methodology also allows generation of numerical differences between solutions that contain different proteins and salts at the same weight concentrations. We showed that the drop drying process is dependent on surfactant concentration, and is sensitive to the action of different external physical factors. In the other words, some of puzzles of a cause-effect chain in informativity of dynamic processes of drying drops were solved. All these data give us grounds to suggest that application of this approach in medical diagnostics, as well as in food and drug quality control should be promising. Further development of the instrumentation is being used to expand our research and develop more applications for medicine and industry.

\section{References}

Aizawa, H., Kurosawa, S., Tozuka, M., Park J-W, Kobayashi K. (2004). Rapid detection of fibrinogen and fibrin degradation products using smart QSM-sensor. Sensors and Actuators B, 2004, 101, 150-154.

Boström M., Williams, D.R.M., Ninham, B.W. (2004) Why the properties of proteins in salt solutions follow a Hofmeister series. Current Opinion in Colloid and Interface Science, 2004, 9, 48-52.

Chang, B.H., Bae, Y.C. (2003). Salting-out in the aqueous single-protein solution: the effect of shape factor. Biophysical. Chemistry, 2003, 104, 523-533.

Chue, X., Jiang, J., Shen, G., and Yu, R. (1996). Salting-out in the aqueous single-protein solution: the effect of shape factor. Analytica Chimica Acta, 1996, 336, 185-193.

Collins, K.D. (1997). Charge density-dependent strength of hydration and biological structure. Biophysical Journal, 1997, 72, 65-76.

Curtis, R.A., Prausnitz, J.M., and Blanch, H.W. (1998). Salting-out in the aqueous singleprotein solution: the effect of shape factor. Biotechnology and Bioengineering, 1998, 57, 11-21.

Deegan, R. D. (2000). Pattern formation in drying drops. Physical Review E, 2000, 61 (1), 475485.

Deegan, R. D., Bakajin, O., Dupont, T. F., Huber, G., Nagel, S.R., and Witten, T.A. (2000). Contact line deposits in an evaporating drop. Physical Review E, 2000, 62 (1), 756765 .

Gilot P., Andre P., and Content J. (1999). Listeria monocytogenes Possesses Adhesins for Fibronectin. Infection and Immunity. Dec. 1999. 67(12): 6698-6701.

Gomes, M.T.C.R. (2001). Is a quartz crystal really a mass sensor? Curr. Topics Anal. Chem., 2001, 2, 187-193. 
Gunning PA, Mackie, AR. Gunning AP, Woodward NC, Wilde PJ \& Morris VJ (2004). The effect of surfactant type on surfactant-protein interactions at the air-water interface. Biomacromolecules, 2004, 5, 984-991.

Heil, W., Koberstein, R., and Zawta, B. (1999). Reference ranges for adults and children. Preanalytical consideration, Roche Diagnostics $\mathrm{GmbH}, 1999$, Mannheim.

Joos, P., Serrien, G. (1999). The principle of Braun-Le Chatelier at surfaces. Journal of Colloid and Interface Science, 1999, 145, 291-294.

Killeen, A., Ossina, N., McGlennen, R.C., Minnerath, S., Borgos, J.,Alexandrov, V., and Sarvazyan, A. (2006). Protein Self-Organization Patterns in Dried Serum Reveal Changes in B-Cell Disorders. Molecular Diagnostics and Therapy, 2006, 10, 6, 371-380.

Konig, B., and Gratzel, M. (1993a). Development of piezoelectric immunosensor for detection of human erythrocytes. Anal. Chim. Acta,1993, 276, 229-233.

Konig, B., and Gratzel, M. (1993b). Detection of human T-lymphocytes with a piezoelectric immunosensor. Anal. Chim. Acta, 1993, 281, 13-18.

Lazarova, V., Spassov, L., Gueorguiev, V., Andreev, S., Malonov, E., Popova, L. (1996). Quartz resonator with $\mathrm{SnO}_{2}$ thin film as acoustic gas-sensor for $\mathrm{NH}_{3}$. Vacuum, 1996, 47 (12), 1423-1425.

Mackie, A.R., Gunninh, A.P., Wilde, P.J., and Morris, V.J. (2000). The competitive displacement of B-lactoglobulin from the air-water interface by SDS. Langmuir, 2000, 16, 8176-8181.

Martin, S.J., and Ricco, A.J. (1987). Acoustic wave viscosity sensor. Appl. Phys. Lett., 1987, 50, 1474-1476.

Mason,W.P. (1964) Physical Acousics. Principles and methods. V.1 A, 592, Academic Press, NY\&L., 1964.

Muramatsu, H., Tamita, E, Karube, I. (1989). Determination of microbes and immunoglobulins using a piezoelectric biosensor. Journal of Membrane Science. 1989, 41, 281-290.

Muschol, M., and Rosenberger, F. (1997). Liquid-liquid phase separation in supersaturated lysozime solutions and associated precipitate formation/crystallization. Journal of Chemical Physics, 1997, 107, 1953-1962.

Nikolaev, A.Ya. (1998). Biological Chemistry, Medical Informative Agency, 1998, Moscow.

Ragoonanan, V., and Aksan, A. (2008). Heterogenity in dessicated solutions: Implications for biostabilization. Biophysical Journal, Match 2008, 94, 2212-2227.

Rapis, E., G. (1988). Well-ordered structure formation during protein film drying. Pis'ma v Zh.T.Ph., 1998, 14, 17, 1560-1565.

Savina, L.V. (1999) Crystalloscopic structures of blood serum of healthy people and patients. Soviet Kuban', 1999, Krasnodar [in Russian].

Shabalin, V.N., Shatokhina, S.N. (2001). Morphology of Biological Fluids, Khrisostom, 2001, Moscow.

Tchukin, E.D., Pertsov A.V., Amelina E.A. (2004). Colloid Chemistry, High School, 2004, Moscow.

Yakhno, T.A., Yakhno, V.G., Levin, G.Ya., Korochkina, O.V., and Buzoverya, M.E. (2001). Dynamics of self-organization processes of biological liquids in the norm state and 
in some diseases. Proceedings of the IVth International Conference on Mathematical Modeling, 2, 265-275, Moscow, 27 June-1 July 2000, STANKIN, Moscow, 2001.

Yakhno, T.A., Yakhno, V.G., Sanin, A.G., and Shmelev, I.I. (2002). Study of the dynamics of phase transitions in liquids of different types by measuring the acoustomechanical impedance of a drying drop. Biophysics, 2002, 47, 6, 1101-1105.

Yakhno, T.A., Yakhno, V.G., Sanin, A.G., Sanina, O.A., and Pelyushenko, A.S. (2003). A Method for Liquid Analysis by means of Phase Transitions during drop drying. Proceedings of SPIE, Bioengineered and Bioinspired Systems, 5119, 87-99, Maspalomas, Gran Canaria, Spain, 19-21 May 2003, SPIE, Maspalomas.

Yakhno, T.A., Yakhno, V.G., Sanin, A.G., Sanina, O.A., and Pelyushenko, A.S. (2004). Protein and salt: spatiotemporal dynamics of events in a drying drop. Technical Physics, 2004, 49, 8, 1055-1063.

Yakhno, T., Yakhno, V., Sanin, A., Egorova, N., Terentiev, I., and Smetanina, V. (2005). The informative-capacity phenomenon of drying drops. Aptitude test in medical diagnostics. IEEE Engineering in Medicine and Biology Magazine, 2005, 24, 2, 96-104.

Yakhno, T., Kazakov, V., Sanin, A., Shaposhnikova, O., and Chernov, A. (2007a). Mechanical properties of adsorption layers in solutions of human blood serum proteins: a comparative assessment. Technical Pphysics, 2007, 52, 4, 510-512.

Yakhno, T., Sanin, A., Pelyushenko, A., Kazakov, V., Shaposhnikova, O., Chernov, A., Yakhno, V., Vacca, C. ,Falcone, F., Johnson B. (2007b). Uncoated quartz resonator as a universal biosensor. Biosensors and Bioelectronics, 2007, 22, 9-10, 2127-2131.

Yakhno T. (2008) Salt-induced protein phase transitions in drying drops. Journal of Colloid and Interface Science, 2008, 318, 225-230.

Yakhno, T.A., Yakhno, V.A. (2009) Structural evolution of drying drops of biological fluids (2009) Technical physics, 2009, vol. 54, No 8, 1219-1227.

Yamasaki A., Cunha, M.A.S.D.A., Oliveira, J.A.B.P., Duarte, A.C., Gomes, M.T.S.R. (2004). Assessment of copper toxicity using an acoustic wave sensor. Biosensors and Bioelectronics, 2004, 19, 1203-1208.

Zhou, R., Vaihinger, S., Geckeler, K.E., Gopel, W. (1994). Reliable $\mathrm{CO}_{2}$ sensor with siliconbased polymers on quartz microbalance transducers. Sensors and Actuators B, 1884, $19,1-3,415-420$. 


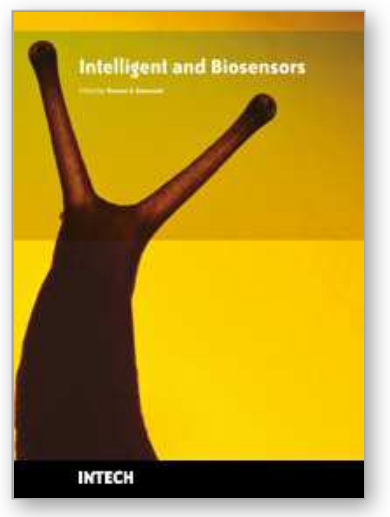

\author{
Intelligent and Biosensors \\ Edited by Vernon S. Somerset
}

ISBN 978-953-7619-58-9

Hard cover, 386 pages

Publisher InTech

Published online 01, January, 2010

Published in print edition January, 2010

The use of intelligent sensors have revolutionized the way in which we gather data from the world around us, how we extract useful information from that data, and the manner in which we use the newly obtained information for various operations and decision making. This book is an attempt to highlight the current research in the field of Intelligent and Biosensors, thereby describing state-of-the-art techniques in the field and emerging new technologies, also showcasing some examples and applications.

\title{
How to reference
}

In order to correctly reference this scholarly work, feel free to copy and paste the following:

Tatiana Yakhno, Anatoly Sanin, Vyacheslav Kazakov, Olga Sanina, Christina Vacca, Frank Falcione, and Vladimir Yakhno (2010). Uncoated Quartz Resonator as a Universal Biosensor, Intelligent and Biosensors, Vernon S. Somerset (Ed.), ISBN: 978-953-7619-58-9, InTech, Available from:

http://www.intechopen.com/books/intelligent-and-biosensors/uncoated-quartz-resonator-as-a-universalbiosensor

\section{INTECH}

open science | open minds

\section{InTech Europe}

University Campus STeP Ri

Slavka Krautzeka 83/A

51000 Rijeka, Croatia

Phone: +385 (51) 770447

Fax: +385 (51) 686166

www.intechopen.com

\section{InTech China}

Unit 405, Office Block, Hotel Equatorial Shanghai

No.65, Yan An Road (West), Shanghai, 200040, China

中国上海市延安西路 65 号上海国际贵都大饭店办公楼 405 单元

Phone: +86-21-62489820

Fax: +86-21-62489821 
(C) 2010 The Author(s). Licensee IntechOpen. This chapter is distributed under the terms of the Creative Commons Attribution-NonCommercialShareAlike-3.0 License, which permits use, distribution and reproduction for non-commercial purposes, provided the original is properly cited and derivative works building on this content are distributed under the same license. 